\section{Trinexapac-ethyl Restricts Shoot Growth and Prolongs Stand Density of 'Meyer' Zoysiagrass Fairway Under Shade}

\author{
E.H. Ervin ${ }^{1}$ \\ Crop and Soil Environmental Sciences Department, Virginia Polytechnic \\ Institute and State University, Blacksburg, VA 24061 \\ C.H. Ok ${ }^{2}$, B.S. Fresenburg ${ }^{3}$, and J.H. Dunn ${ }^{4}$ \\ Department of Horticulture, University of Missouri, Columbia, MO 65211
}

Additional index words. plant growth retardant, turfgrass, tiller density, Zoysia japonica

\begin{abstract}
Meyer' zoysiagrass (Zoysia japonica Steud.) is a popular turfgrass species for transition zone golf course fairways and tees because it is generally winter hardy while providing an excellent playing surface with minimal chemical and irrigation inputs. However, its functionality declines readily on many of the shaded areas on these courses. Reduced irradiance causes excessive shoot elongation, reduced tillering, and weak plants that are poorly suited to tolerate or recover from traffic and divoting. Trinexapacethyl (TE) effectively reduces gibberellic acid (GA) biosynthesis and subsequent shoot cell elongation. The objective of this study was to determine if monthly applications of TE would reduce shoot elongation of 'Meyer' zoysiagrass and improve stand persistence under two levels of shade. Shade structures were constructed in the field that continuously restricted $77 \%$ and $89 \%$ irradiance. A mature stand of 'Meyer' was treated with all combinations of three levels of shade $(0 \%, 77 \%$, and $89 \%)$ and three levels of monthly TE application [0, $48 \mathrm{~g} \cdot \mathrm{ha}^{-1}$ a.i. $(0.5 \times)$, and $96 \mathrm{~g} \cdot \mathrm{ha}^{-1}$ a.i. $\left.(1 \times)\right]$ in 1998 and 1999 . In full sun, the $0.5 \times$-rate reduced clipping production by $17 \%$ to $20 \%$ over a four-week period and the $1 \times$-rate by $30 \%$ to $37 \%$. Monthly application of TE at the $1 \times$-rate increased 'Meyer' tiller density in full sun and under $77 \%$ shade. Both rates of TE consistently reduced shoot growth under shade relative to the shaded control. Only the monthly applications at the $1 \times$-rate consistently delayed loss of quality under $77 \%$ shade. The zoysiagrass persisted very poorly under $89 \%$ shade whether treated or not with TE and plots were mostly dead at the end of the experiment. Our results indicate TE can be an effective management practice to increase 'Meyer' zoysiagrass persistence in shaded environments. Chemical name used: 4-cyclopropyl- $\alpha$-hydroxy-methylene-3,5-dioxocyclohexanecarboxylic acid ethyl ester (trinexapac-ethyl)
\end{abstract}

Up to $25 \%$ of the turf managed in the U.S. is shaded (Dudeck and Peacock, 1992; Beard, 1973). Reduced light intensity has a number of deleterious morphological and physiological consequences. These include increased shootto-root ratios, decreased specific leaf weight, thinner leaf blades, decreased photosynthesis, decreased carbohydrate production, and less tillering (Qian and Engelke, 1999; Qian et al., 1998; Dudeck and Peacock, 1992; Kephart et al., 1992).

Cool-season (C3) grasses are generally more shade tolerant than $\mathrm{C} 4$ grasses, with light saturation points at $\approx 50 \%$ and $100 \%$ of full sunlight, respectively (Salisbury and Ross, 1992; Danneberger, 1993). Growth and per-

Received for publication 28 Dec. 2002. Accepted for publication 5 Sept. 2001. Research supported by the Missouri Valley Turfgrass Association, the Mississippi Valley Golf Course Superintendent's Association, and the Univ. of Missouri Agricultural Experiment Station. Publication No. 13098.

${ }^{1}$ Assistant Professor.

${ }^{2}$ Graduate Research Assistant.

${ }^{3}$ Research Associate.

${ }^{4}$ Professor. sistence of $\mathrm{C} 3$ turfgrasses has been reported at irradiance levels between $5 \%$ to $20 \%$ of full sunlight (Beard, 1965; Stier et al., 1999), while some Zoysia and Cynodon species and varieties have been reported to persist with a minimum acceptable quality at $10 \%$ to $40 \%$ full sunlight (Qian and Engelke, 1999; Riffell et al., 1995; McBee and Holt, 1966).

Increased biosynthesis of GA has been associated with excessive shoot elongation of field pea (Pisum sativum L.) (Gawronska et al., 1995) and Kentucky bluegrass (Poa pratensis L.) (Tan and Qian, 2000) in response to low light intensity. Promotion of shoot elongation due to increased GA concentration is a common shade avoidance mechanism of plants, but is a net-energy losing response in turfgrass where such increased leaf area is regularly removed by mowing. This response coupled with a number of other factors such as reduced photosynthesis, reduced rooting, greater tissue succulence, and increased susceptibility to damage from pests imply that shaded portions of zoysiagrass golf course fairways and tees are poorly suited to tolerate or recover from traffic and divoting.
Trinexapac-ethyl (TE) is an effective antigibberellic acid type plant growth retardant (PGR) that blocks the 3b-hydroxylase production of $\mathrm{GA}_{1}$ (Adams et al., 1992) and markedly reduces shoot growth of cool- and warmseason turfgrass species (Ervin and Koski, 1998, 2001; Fagerness and Penner, 1998; Wiecko, 1997, Johnson, 1993, 1994). Use of TE on shaded turf should reduce $\mathrm{GA}_{1}$ biosynthesis and shoot elongation resulting in conserved photosynthate and greater quality maintenance. In greenhouse and polyhouse studies with shaded Diamond zoysiagrass [Zoysia matrella (L.) Merr.] Qian et al., 1998 and Qian and Engelke (1999) reported reduced shoot growth and greater canopy photosynthesis, nonstructural carbohydrates, tiller density, root mass, and quality due to TE treatment. Greatest turf quality under $85 \%$ to $90 \%$ shade was reported when Diamond zoysiagrass received monthly treatments of TE at $48 \mathrm{~g} \cdot \mathrm{ha}^{-1}$ a.i. Four years of testing at a live oak [Quercus virginiana (Mill.)] site in Texas that provided $\approx 90 \%$ shade indicated that $Z$. matrella genotypes maintained $52 \%$ to $75 \%$ cover, while the commercial standard-Z.japonica 'Meyer' maintained only $27 \%$ cover (Riffell et al., 1995). Given this information, our hypothesis was that TE would improve the persistence of shaded, field-maintained 'Meyer' zoysiagrass, but further information was needed on the limits of 'Meyer's shade tolerance and the best TE rates for extending those limits. Thus, our objectives were to determine if TE would improve the shade tolerance of field-maintained, fairway-height 'Meyer' zoysiagrass and, if so, which TE rate would be most effective.

\section{Materials and Methods}

This study was conducted on a mature stand of 'Meyer' zoysiagrass managed as a fairway at the Univ. of Missouri Turfgrass Research Center. The experimental area was irrigated once a week to replace $100 \%$ of estimated evapotranspiration and supplied with $\mathrm{N}$ at $49 \mathrm{~kg} \cdot \mathrm{ha}^{-1}$ from urea in June and August of each year. The experimental 'Meyer' fairway had been in place at least 15 years over a Mexico silt loam (fine, montmorillonitic, mesic Mollic Endoaqualfs) with a pH of 6.5, organic matter of $4.9 \%, 92 \mathrm{~kg} \cdot \mathrm{ha}^{-1} \mathrm{P}$, and $442 \mathrm{~kg} \cdot \mathrm{ha}^{-1}$ $\mathrm{K}$. The study consisted of two factors and four replications arranged in randomized complete blocks. The two factors were shade level and TE rate. Shade levels were: $0 \%$ shade, $73 \%$ shade cloth, and $92 \%$ shade cloth (Stuppy Greenhouse Manufacturing, Kansas City, Mo.). These shade levels were selected based on two factors. First, previous research by Qian and Engelke, indicated that Zoysia matrella 'Diamond' persisted under $73 \%$ shade without TE-treatment and up to $88 \%$ shade when treated monthly with TE. Second, measurements made on shaded and thinning 'Meyer' zoysiagrass fairways on golf courses in the Saint Louis area indicated that many of these fairways were in $90 \%$ shade for large portions of the day (Ervin, unpublished data). For the purposes of this study, the $73 \%$ treat- 
ment was considered a moderately-heavy shade level, while the $92 \%$ was considered heavy shade.

Trinexapac-ethyl rates were: $0,48 \mathrm{~g} \cdot \mathrm{ha}^{-1}$ a.i. $(0.5 \times$-rate $)$, and $96 \mathrm{~g} \cdot \mathrm{ha}^{-1}$ a.i. (1×-rate). The 36 experimental units $(4 \times 3 \times 3)$ were $2.1 \mathrm{~m} \times 1.5 \mathrm{~m}$ each, separated by a $1.5 \mathrm{~m}$ border. Shade cloths were mounted on copper pipe frames and supported $76 \mathrm{~cm}$ above the turf canopy. The shade cloth was draped on all sides down to $15 \mathrm{~cm}$ above the turf canopy to prevent the effect of incline light. To quantify relative shade levels, photon flux densities in $\mu \mathrm{mol} \cdot \mathrm{m}^{-2} \cdot \mathrm{s}^{-1}$ were taken with a quantum radiometer (model LI-190SA; LI-COR, Lincoln, Nebr.) from 1100 to $1400 \mathrm{HR}$ on four cloud free days: 20 Aug. 1998, 26 Sept. 1998, 14 June 1999, and 21 Aug. 1999.

Shade and monthly TE treatments began simultaneously on 14 Aug. 1998. The second TE application was on 13 Sept. 1998. Shade structures were removed on 15 Nov. 1998 to correspond with deciduous leaf fall. Shade structures were replaced on 1 May 1999 and remained until 1 Oct. 1999. The TE treatment dates in 1999 were: 28 May, 25 June, 23 July, and 20 Aug.

Turf quality was visually assessed monthly on a 1 (poorest) to 9 (best) scale; ratings of $<6$ were considered unacceptable. The estimation of turf quality was based on the primary components of color, density, texture, and uniformity of the zoysiagrass surface.

To determine clipping yield, a $0.6-\mathrm{m}^{2}$ swath was cut weekly with a standard reeltype greens-mower at $16 \mathrm{~mm}$, clippings were collected, dried for $24 \mathrm{~h}$ at $70^{\circ} \mathrm{C}$, and weighed. Weekly clipping weight data are presented, in $\mathrm{g} \cdot \mathrm{m}^{-2}$, as the deviation from that of the fullsun control. Lines connecting data points do not represent actual or mathematically predicted data. These artificially smoothed lines have merely been added by the computer software (SigmaPlot 2000; SPSS, Chicago) so as to provide the reader with a sense of week to week clipping yield dynamics. Shade structures were removed once a week for $\approx 2$ $\mathrm{h}$ to facilitate mowing, traffic, and irrigation. Immediately following weekly mowing, and prior to the irrigation event, each experimental unit received 10 evenly distributed golf cart passes. The golf cart has smooth turf tires, was driven at a moderate speed $(\approx 2.7$ $\left.\mathrm{m} \cdot \mathrm{s}^{-1}\right)$, and weighs $270 \mathrm{~kg}$. Golf cart traffic was applied to all plots in an attempt to make the results of this research more applicable to actual golf course fairway conditions.

Tiller number was determined after using a core sampler (7 $\mathrm{cm}$ in diam.) to remove two cores per plot on 17 Aug. 1998 (initial), 02 June 1999, and 09 Aug. 1999. Immediately after harvesting, cores were cut along the soil/ thatch interface and tiller numbers were counted.

Average photon flux densities during clearsky conditions (in $\mu \mathrm{mol} \cdot \mathrm{m}^{-2} \cdot \mathrm{s}^{-1}$ ) were 1634 on unshaded plots, 371 under $73 \%$ shade cloth, and 176 under $92 \%$ shade cloth. These values correspond to $0 \%$ shade, $77 \%$ shade, and $89 \%$ shade, respectively and will be used to designate the shade levels in this study. Qian and
Engelke (1999) reported a light compensation point of $270 \mu \mathrm{mol} \cdot \mathrm{m}^{-2} \cdot \mathrm{s}^{-1}$ for Zoysia matrella grown under $86 \%$ shade. If this value is representative of the light compensation point for Zoysia japonica, we would predict that under continuous clear sky conditions the $77 \%$ plots would be able to maintain a positive energy balance, while the $89 \%$ plots would not.

Analysis of variance was conducted on turf quality, clipping dry weight, and tiller number data for this standard $3 \times 3$ factorial with the Michigan State Statistical Program v. 2.10 (MSTAT-C, 1993). Treatment means were separated using Fisher's protected least significant difference (LSD).

\section{Results and Discussion}

In full sun conditions, the $1 \times$-rate of TE reduced clipping dry weight at $1,2,4,5,7$, and

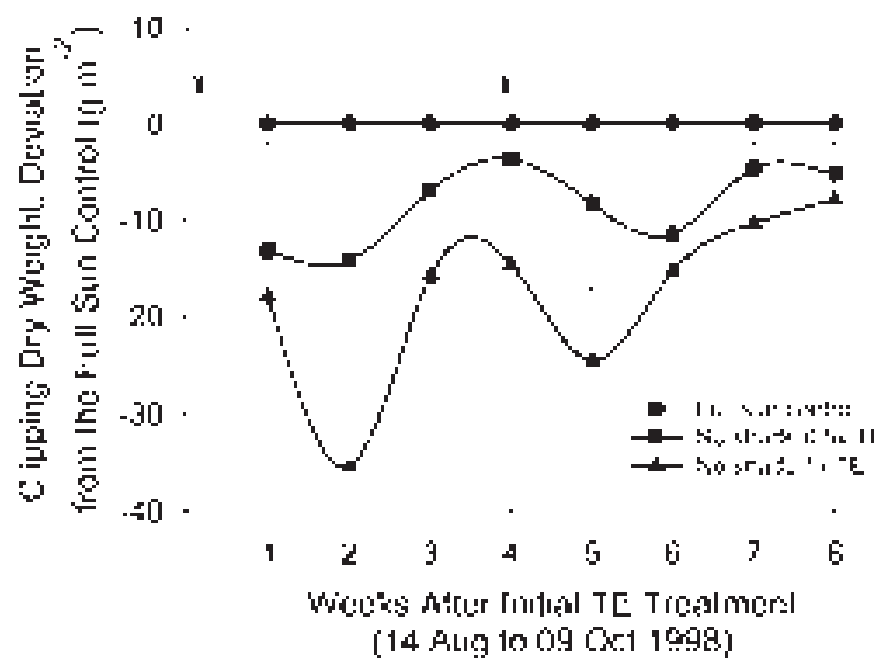

Fig. 1. Clipping dry weight response effected by $0.5 \times$ and $1 \times$ rates of trinexapac-ethyl (TE) and the control on 'Meyer' zoysiagrass in the field from 14 Aug. to 9 Oct. 1998. Vertical bars represent $\operatorname{LSD}_{0.05}$ and arrows indicate TE applications; lines between data points have been smoothed, they are not splined curves.

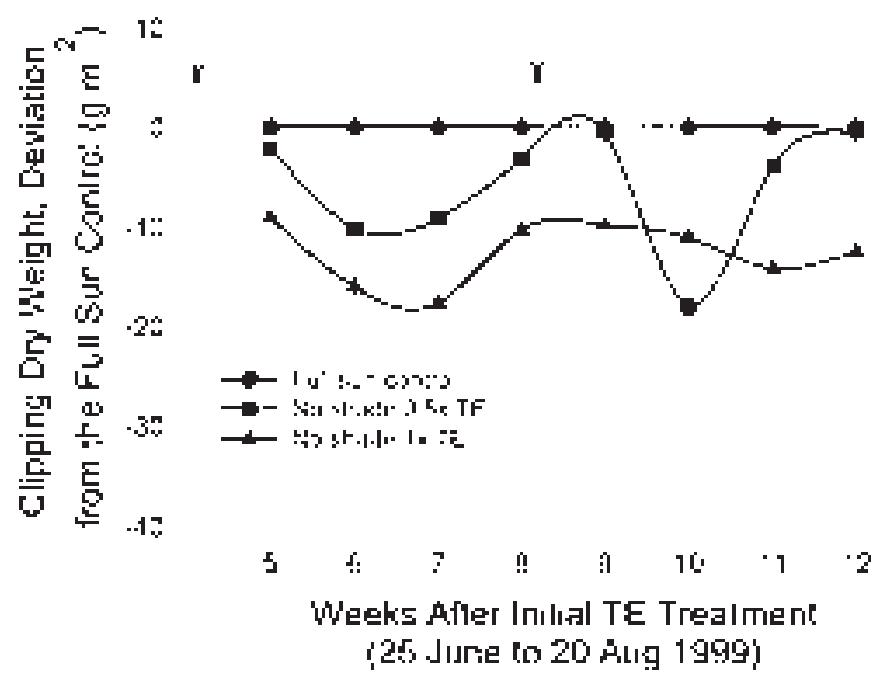

Fig. 2. Clipping dry weight response effected by $0.5 \times$ and $1 \times$ rates of trinexapac-ethyl (TE) and the control on 'Meyer' zoysiagrass in the field from 25 June to 20 Aug. 1999. Vertical bars represent $\mathrm{LSD}_{0.05}$ and arrows indicate TE applications; lines between data points have been smoothed, they are not splined curves. 


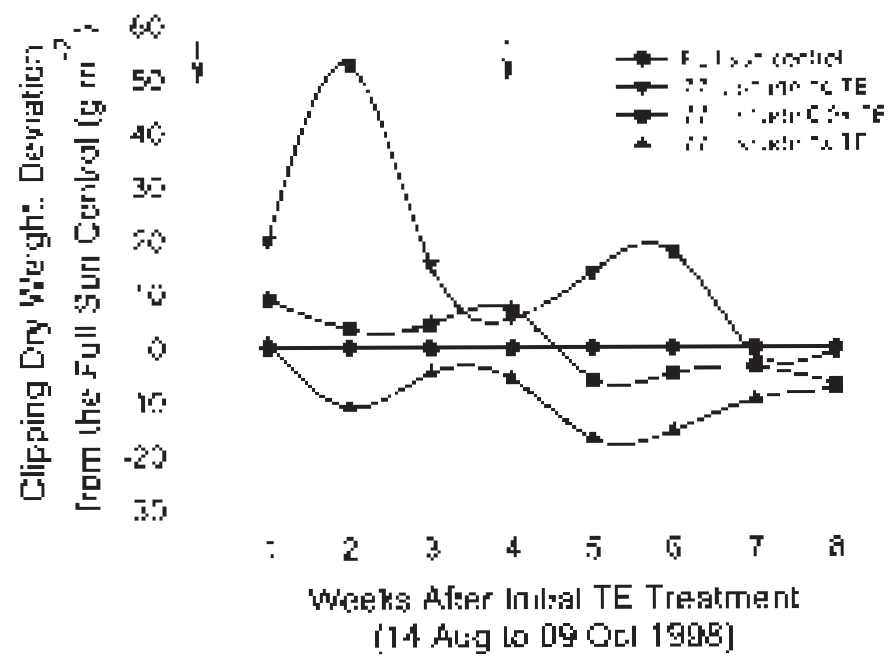

Fig. 3. Clipping dry weight response effected by the interaction of $77 \%$ shade and $0.5 \times$ and $1 \times$ rates of trinexapac-ethyl (TE) and the controls on 'Meyer' zoysiagrass in the field from 14 Aug. to 9 Oct. 1998. Vertical bars represent $\mathrm{LSD}_{0.05}$ and arrows indicate TE applications; lines between data points have been smoothed, they are not splined curves.
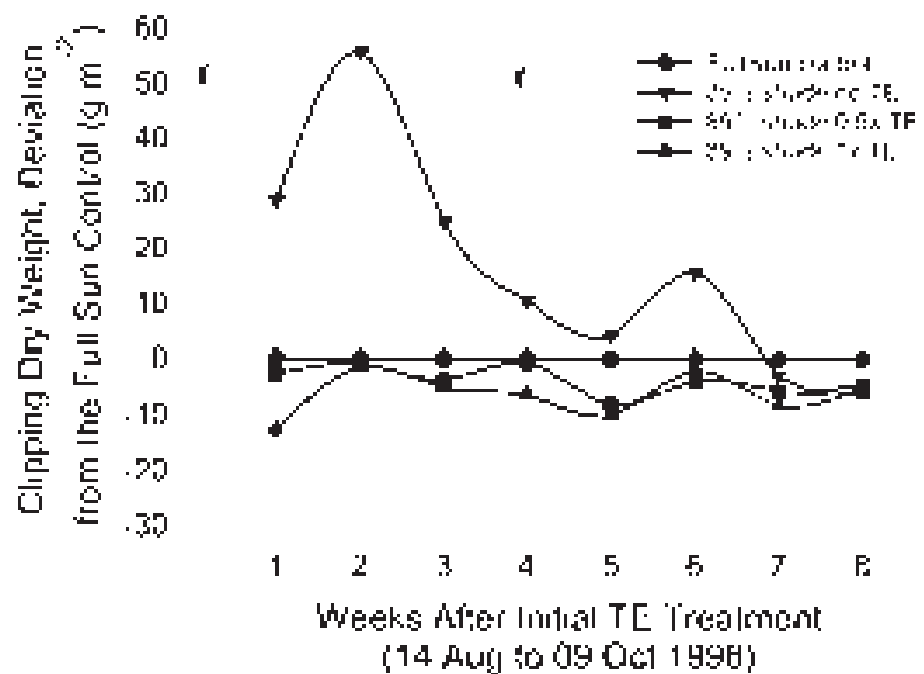

Fig. 4. Clipping dry weight response effected by the interaction of $89 \%$ shade and $0.5 \times$ and $1 \times$ rates of trinexapac-ethyl (TE) and the controls on 'Meyer' zoysiagrass in the field from 14 Aug. to 9 Oct. 1998. Vertical bars represent $\mathrm{LSD}_{0.05}$ and arrows indicate $\mathrm{TE}$ applications; lines between data points have been smoothed, they are not splined curves.

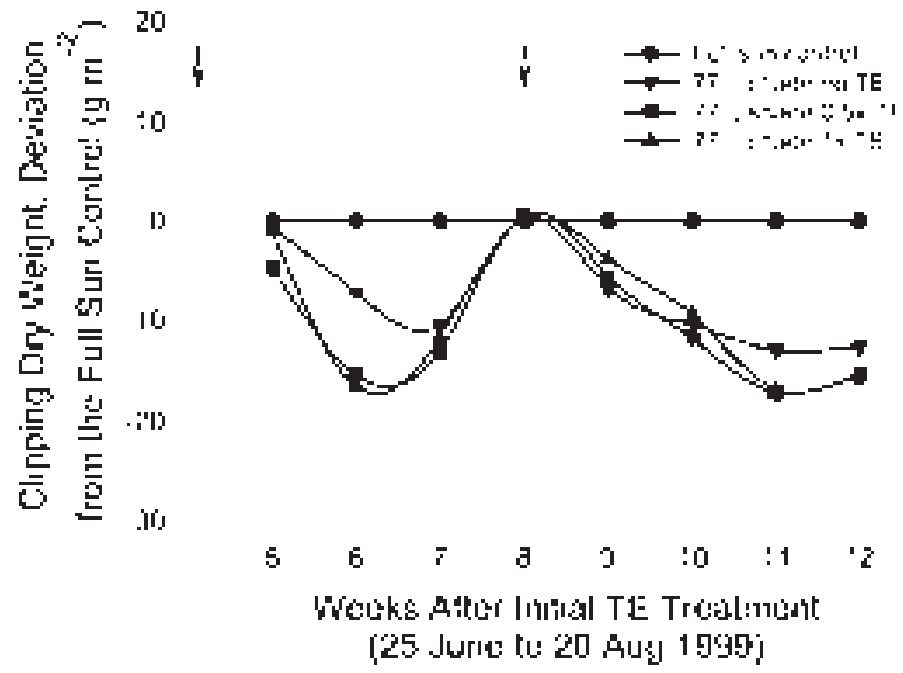

Fig. 5. Clipping dry weight response effected by the interaction of $77 \%$ shade and $0.5 \times$ and $1 \times$ rates of trinexapac-ethyl (TE) and the controls on 'Meyer' zoysiagrass in the field 25 June to 20 Aug. 1999. Vertical bars represent $\mathrm{LSD}_{0.05}$ and arrows indicate TE applications; lines between data points have been smoothed, they are not splined curves.
Clipping production remained enhanced from 2 to 6 WAIT under $77 \%$ shade and from 1 to 4 WAIT under $89 \%$ shade. This expected response was most likely due to increased endogenous $\mathrm{GA}_{1}$ levels in reduced light, as has been demonstrated recently for Kentucky bluegrass (Tan and Qian, 2000). Growth enhancement under $77 \%$ and $89 \%$ shade and no TE subsided at 7 WAIT, perhaps indicating a point where energy reserves had been largely depleted.

Trinexapac-ethyl significantly reduced shoot growth at the $1 \times$-rate from 2 to 8 WAIT and 1 to 5 WAIT under $77 \%$ and $89 \%$ shade, respectively in 1998 (Figs. 3 and 4). Shoot growth of the TE-treated zoysia under $77 \%$ and $89 \%$ shade was less than or equal to the full sun control for the entire 8-week period. Thus, much energy-consuming shoot growth was eliminated by the use of TE on shaded 'Meyer' zoysiagrass.

From 1 to 4 WAIT in 1999 (28 May to 24 June), clipping production responses were similar to those reported during 1998 (data not shown). For example, in full sun, the $1 \times$ TE rate reduced clipping dry weight by an average of $30 \%$, while under $77 \%$ shade, clipping production was increased by $20 \%$ (no TE) or unchanged $(1 \times \mathrm{TE})$. Compared to the 1998 data where shade treatment without TE increased growth for up to 6 WAIT, growth enhancement only persisted for 4 WAIT in 1999. These results are most likely an indication of the cumulative energy depleting effects of shade treatment and traffic. This energy depletion supposition is supported by data from 5 to 12 WAIT in 1999, where 'Meyer' clipping production was reduced by similar amounts relative to the full sun control under both levels of shade whether treated with TE or not (Figs. 5 and 6). Both the 1998 and 1999 clipping production data indicate that untreated 'Meyer' zoysiagrass under $77 \%$ or greater shade begins to have a negative energy balance after continuous shade for eight weeks or longer. The shaded, TE-treated plants may be using energy faster than they can replace under this situation. However, because less energy was expended on shoot growth during the first eight weeks of shade, the duration of adequate stand persistence should be increased. The visual quality and tiller density data support this supposition.

Trinexapac-ethyl had no effect on the visual quality of 'Meyer' in full sun conditions over the course of the study (Table 1). About 8 weeks of shade treatment, however, reduced 'Meyer' quality significantly (9 Oct. 1998). Two applications of TE over this period, on both $77 \%$ and $89 \%$ shade plots, served to partially alleviate these quality reductions, especially the $1 \times$-rate. By 18 June 1999 , following 7 weeks of shade and 3 WAIT, greater quality was maintained at $77 \%$ shade due to the 1X-rate of TE. For the remainder of the study, only the $1 \times$-rate under $77 \%$ shade retained higher quality relative to the other shaded treatments.

Tiller density counts at the beginning of the study indicated no differences (Table 2). A second assessment, on 2 June 1999, again indicated no clear differences. However, the final assessment on 9 Aug., indicated clear 


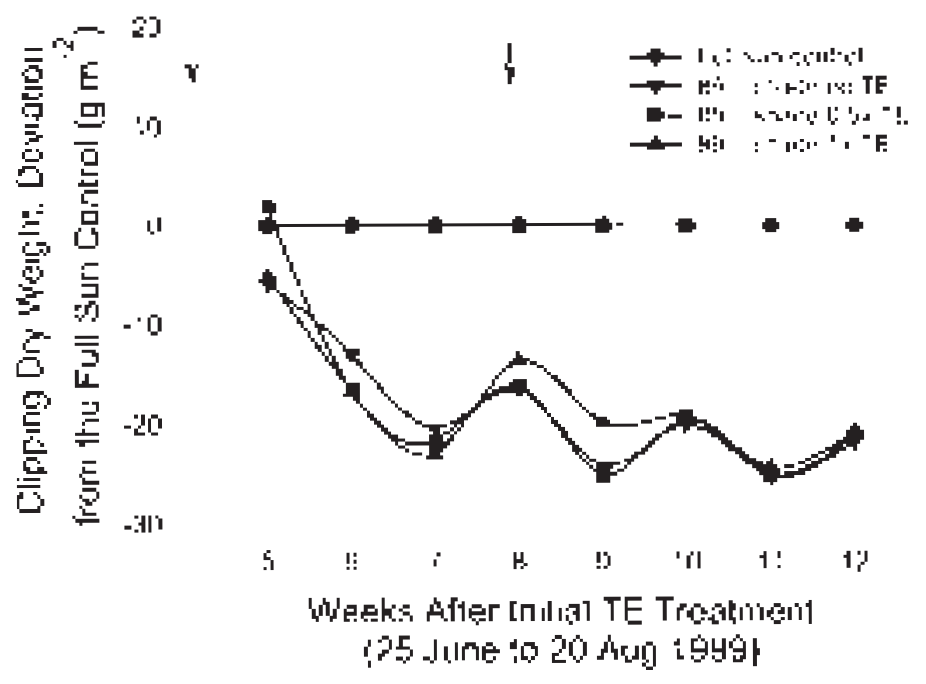

Fig. 6. Clipping dry weight response effected by the interaction of $89 \%$ shade and $0.5 \times$ and $1 \times$ rates of trinexapac-ethyl (TE) and the controls on 'Meyer' zoysiagrass in the field 25 June to 20 Aug. 1999. Vertical bars represent $\mathrm{LSD}_{0.05}$ and arrows indicate TE applications; lines between data points have been smoothed, they are not splined curves.

Table 1 . Visual quality response of 'Meyer' zoysiagrass to shade and trinexapac-ethyl.

\begin{tabular}{|c|c|c|c|c|c|}
\hline Treatment & 15 Aug. 98 & 09 Oct. 98 & 18 June 99 & 18 July 99 & 23 Aug. 99 \\
\hline & \multicolumn{5}{|c|}{------- Quality rating ( $1-9$ scale; $9=$ best $)-------$} \\
\hline No shade + no TE & 7.5 & $7.5 \mathrm{a}$ & $6.9 \mathrm{a}$ & $6.0 \mathrm{a}$ & $6.3 \mathrm{a}$ \\
\hline No shade $+0.5 \times \mathrm{TE}$ & 7.5 & $7.5 \mathrm{a}$ & $6.9 \mathrm{a}$ & $5.6 \mathrm{a}$ & $6.4 \mathrm{a}$ \\
\hline No shade $+1 \times \mathrm{TE}$ & 7.5 & $7.4 \mathrm{a}$ & $6.8 \mathrm{a}$ & $6.3 \mathrm{a}$ & $6.0 \mathrm{a}$ \\
\hline $77 \%$ shade + no TE & 7.5 & $5.1 \mathrm{de}$ & $4.9 \mathrm{c}$ & $3.3 \mathrm{c}$ & $1.9 \mathrm{c}$ \\
\hline $77 \%$ shade $+0.5 \times \mathrm{TE}$ & 7.5 & $6.3 \mathrm{bc}$ & $5.1 \mathrm{bc}$ & $3.4 \mathrm{c}$ & $2.4 \mathrm{c}$ \\
\hline $77 \%$ shade $+1 \times \mathrm{TE}$ & 7.5 & $6.5 \mathrm{~b}$ & $5.8 \mathrm{~b}$ & $4.5 \mathrm{~b}$ & $3.5 \mathrm{~b}$ \\
\hline $89 \%$ shade + no TE & 7.5 & $4.3 \mathrm{e}$ & $4.5 \mathrm{c}$ & $1.6 \mathrm{e}$ & $1.0 \mathrm{~d}$ \\
\hline $89 \%$ shade $+0.5 \times \mathrm{TE}$ & 7.5 & $5.6 \mathrm{~cd}$ & $5.0 \mathrm{bc}$ & $1.9 \mathrm{de}$ & $1.0 \mathrm{~d}$ \\
\hline $89 \%$ shade $+1 \times$ TE & 7.5 & $6.4 \mathrm{~b}$ & $5.3 \mathrm{bc}$ & $2.5 \mathrm{~d}$ & $1.3 \mathrm{~d}$ \\
\hline $\operatorname{LSD}_{0.05}$ & NS & 0.8 & 0.8 & 0.6 & 1.1 \\
\hline
\end{tabular}

Ns Nonsignificant.

Table 2. Tiller density response of 'Meyer' zoysiagrass to shade and trinexapacethyl.

\begin{tabular}{|c|c|c|c|}
\hline Treatment & 17 Aug. 1998 & 2 June 1999 & 9 Aug. 1999 \\
\hline & ---- & Tiller density (no. $\mathrm{dm}^{-2}$ ) & ---- \\
\hline No shade + no TE & 204.8 & 227.6 & $301.0 \mathrm{~b}$ \\
\hline No shade $+0.5 \times \mathrm{TE}$ & 222.5 & 256.4 & $270.3 \mathrm{~b}$ \\
\hline No shade $+1 \times \mathrm{TE}$ & 244.0 & 232.8 & $338.0 \mathrm{a}$ \\
\hline $77 \%$ shade + no TE & 251.6 & 231.4 & $45.4 \mathrm{~d}$ \\
\hline $77 \%$ shade $+0.5 \times \mathrm{TE}$ & 231.4 & 203.4 & $63.3 \mathrm{~cd}$ \\
\hline $77 \%$ shade $+1 \times \mathrm{TE}$ & 211.3 & 207.9 & $89.3 \mathrm{c}$ \\
\hline $89 \%$ shade + no TE & 241.1 & 222.0 & $3.3 \mathrm{e}$ \\
\hline $89 \%$ shade $+0.5 \times$ TE & 232.9 & 249.6 & $9.3 \mathrm{e}$ \\
\hline $89 \%$ shade $+1 \times \mathrm{TE}$ & 231.8 & 199.8 & $30.6 \mathrm{de}$ \\
\hline $\mathrm{LSD}_{005}$ & NS & NS & 36.1 \\
\hline
\end{tabular}

${ }^{\mathrm{N} N}$ Nonsignificant.

treatment differences. Monthly application of $\mathrm{TE}$ at the $1 \times$-rate increased 'Meyer' tiller density in full sun and under $77 \%$ shade. Increased tiller density following multiple monthly applications of TE under full sun conditions in the field have been reported for Kentucky bluegrass (Ervin and Koski, 2001). Qian andEngelke (1999) also reported greater maintenance of Zoysia matrella tiller density following multiple monthly TE applications under $86 \%$ shade in the greenhouse.

Dense shade treatments increased 'Meyer' zoysiagrass clippings for approximately four to six weeks. Shade treatment for six weeks or more resulted in lower shoot growth relative to the full sun control and significant loss of quality due to increased senescence. Monthly $1 \times$-rate applications of the antigibberellic acid PGR, TE, on shaded 'Meyer' zoysiagrass effectively suppressed the promotion of shoot elongation by reduced light intensity and delayed senescence, loss of quality, and tiller thinning. However, TE-treatment still resulted in commercially unacceptable quality levels under $89 \%$ shade. Further research is needed investigating lower shade levels (50\% to $75 \%$ ) and the most effective frequency and rates of TE treatment that will enable the maintenance of commercially acceptable 'Meyer' zoysiagrass fairways and tees.

\section{Literature Cited}

Adams, R., E. Kerber, K. Pfister, and E.W. Weiler. 1992. Studies on the action of the new growth retardant CGA 163'935 (cimectacarb), p. 818827. In: C.M. Karssen, L.C. van Loon, and D. Vreugdenhil (eds.). Progress in plant growth regulation. Kluwer Academic, Dordrecht, The Netherlands.

Beard, J.B. 1965. Factors in the adaptation of turfgrasses to shade. Agron. J. 57:457-459.

Beard, J.B. 1973. Turfgrass: Science and culture. Prentice-Hall, Englewood Cliffs, N.J.

Danneberger, T.K., Jr. 1993. Turfgrass ecology and management. G.I.E. Inc., Cleveland, Ohio.

Dudeck, A.E. and C.H. Peacock. 1992. Shade and turfgrass culture, p. 269-284. In: D.V. Waddington, R.N. Carrow, and R.C. Shearman (eds.). Turfgrass. Amer. Soc. Agron. Monograph No. 32. Madison, Wisc.

Ervin, E.H. and A.J. Koski. 2001. Kentucky bluegrass growth responses to trinexapac-ethyl, traffic, and nitrogen. Crop Sci. 41(6):18711877.

Ervin, E.H., and A.J. Koski.1998. Growth responses of Lolium perenne L. to trinexapac-ethyl. HortScience 33:1200-1202.

Fagerness, M.J. and D. Penner. 1998. Evaluation of V-10029 and trinexapac-ethyl for annual bluegrass seedhead suppression and growth regulation of five cool-season turfgrass species. Weed Technol. 12:436-440.

Gawronska, H., Y. Yang, K. Furukawa, R.E. Kendrick, N. Takahashi, and Y. Kamiya. 1995. Effects of low irradiance stress on gibberellin levels in pea seedlings. Plant Cell Physiol. 36:1361-1367.

Johnson, B.J. 1993. Response of tall fescue to plant growth regulators and mowing frequencies. J. Environ. Hort. 11:163-167.

Johnson, B.J. 1994. Influence of plant growth regulators and mowing on two bermudagrasses. Agron. J. 86:805-810.

Kephart, K.D., D.R. Buxton, and S.E. Taylor. 1992. Growth of $\mathrm{C}_{3}$ and $\mathrm{C}_{4}$ perennial grasses under reduced irradiance. Crop Sci. 32:1033-1038.

MSTAT-C. 1993. User's guide to MSTAT-C. Michigan State Univ., E. Lansing.

Qian, Y.L. and M.C. Engelke. 1997. Diamond zoysiagrass as affected by light intensity. J. Turf. Mgmt. 3(2):1-13.

Qian, Y.L., M.C. Engelke, M.J.V. Foster, and S. Reynolds. 1998. Trinexapac-ethyl restricts shoot growth and improves quality of Diamond Zoysiagrass under shade. HortScience. 33(6):1019-1022.

Qian, Y.L. and M.C. Engelke. 1999. Influence of trinexapac-ethyl on Diamond zoysiagrass in a shade environment. Crop Sci. 39:202-208.

Riffell, S.K., M.C. Engelke, and S.J. Morton. 1995. Performance of three warm-season turfgrasses cultured in shade: Zoysiagrass. Texas Turfgrass Research. Texas Agr. Expt. Sta. PR-turf 95$1: 60-65$.

Salisbury, F.B. and C.W. Ross. Plant physiology, $4^{\text {th }}$ edition. Wadsworth Publishing, Belmont, Calif.

SigmaPlot, 2000. Version 6.00. SPSS Inc. Chicago.

Stier, J.C., J.N. Rogers, III, J.R. Crum, and P.E. Rieke. Flurprimidol effects on Kentucky bluegrass under reduced irradiance. Crop Sci. 39:1423-1430.

Tan, Z.G. and Y.L. Qian. 2000. Effects of light intensity on gibberellic acid contents in Kentucky bluegrass, p. 157. In: Agronomy abstracts. ASA, Madison, Wisc.

Wieko, G. 1997. Response of 'Tifway' bermudagrass to trinexapac-ethyl. J. Turfgrass Mgmt. 2:29-36. 